\title{
The Research on Post-Olympics Economic Downturn Effects
}

\author{
Tiansheng Xu, Xiaoying Liu, Longxin Chen \\ Information. Capital University of Economics and Business \\ Beijing, China \\ xuts@cueb.edu.cn
}

\begin{abstract}
The paper explains the different causes of the economic downturn effects after Olympics in each organizing nation, analyzes the host country's main stock index reaction to economic situation after Olympics and shows the trend and rule in stock market. In the end, it analyzes the highest growth of each host country's main stock index data as well as prominent fluctuation period of them.
\end{abstract}

Keywords-Economic downturn effects; Post-Olympic Economy; The main stock index

\section{INTRODUCTION}

The world's major cities are in the bid to host the Olympic Games, they would like to improve the reputation of the city, speed up urban construction and bring a direct income to the city. However, it is uncertain whether the immediate benefits can truly become the city's long-term interests or not. It is also uncertain if the benefits after Olympics are really greater than the cost for the event. With the economic downturn after the Olympics of the few countries, these two issues attracted the attention of the governments. So the researches on economic downturn effects after the Olympics have become inevitable. We summarize the main causes of economic downturn after Olympics. After analyzed the causes, we focused on the influence of post-Olympic stock markets and obtained the pattern of the markets based on the main stock index data of the host countries. This paper shows the potential relationship between the post-Olympic economic downturn effects and the trend of stock markets.

\section{RELATED RESEARCHES}

The study on the post-Olympic economic downturn effects is mostly concentrated at home. Reference [1] is the most representative and convincing. But the paper was written long time ago, the analysis just stayed in the macroeconomic data. It was short of a more detailed analysis and also don't have any questions about the stock market. In foreign countries, a lot of literature were about the stock market's reaction to the Olympics, most of which remained in the influence of Olympics announced on the host countries' stock markets. They studied the data which was presented a week before and after the declaration of the host city. Take [2] for example. Although their method is of great significance, it is lack of practical because of the small amount of data, the narrow scope of the study and lack of forecast the overall trend of stock market. This paper combined with both, do research on the relationship of the economic impact and the stock market after analyze the causes of post-Olympic economic downturn effects.

\section{EFFECTS OF POST-OLYMPIC ECONOMIC DOWNTURN SINCE 1988}

\section{A. Seoul Olympic Games in 1988}

The net income of Seoul Olympics is at least $\$ 400$ million which really brought rapid development to South Korea's economy. But in fact, economy after the 1988 Seoul Olympics does exist the following questions.

Firstly, industrial structure and economic structure are imbalanced. When South Korea organized the Olympic Games, its industrial structure transformed from laborintensive into a structure based on the capital-intensive. However, the formation of this structure was not compatible with Korea's economic development and the market trends of world. There are some studies showing that South Korea's financial crisis which occurred in the late 1990s related a lot to imbalance of national economic in 1988.

Secondly, the real estate bubble was serious. Seoul Olympics played an important role in the boom in real estate prices. The prices in central region rose sharply and they fell sharply in surrounding areas.

Thirdly, investment slowdown. Because municipal infrastructure was relatively backward, the government invested heavily in infrastructure. Korea maintained a GDP growth rate of more than $11 \%$ for three years before the Olympic. But as the investment was reduced gradually, the GDP from 1989 to 1991 appeared obvious signs of slowdown.

\section{B. Barcelona Olympic Games in 1992}

The post-Olympic economic downturn effects after Barcelona Olympic Games is particularly evident. Its direct expenses and indirect investment are much higher than any previous Olympic Games. The total investment accounted for 5\% of the total GDP of Spain in 1992 and 10\% of the total GDP of Catalan. So, the ultra-high proportion caused a high expectation to net economic. The billions of investment in Barcelona Olympics does promote economic recovery and development of the coastal cities, but it left a heavy economic burden to Catalan. Besides because of the adverse effects of the deterioration of the overall economic situation in Europe after the Olympic Games, Barcelona's economy was even worse. Economic growth rate declined sharply 
from the first half of 1993, even presented a negative economic growth in the second half of the year.

In addition, the post-Olympic economic downturn effects are also reflected in the house prices. According to statistics, house prices in Barcelona increased by 300\% during the 6 years before the Olympics, and the prices of house which were surrounding the Olympic village increased by $325 \%$. The real estate bubble exploded rapidly after the Olympic Games. In 1993, real estate prices fell back to the level of previous Olympic Games quickly in a short period of time.

\section{Atlanta Olympic Games in 1996}

Atlanta Olympic Games is a rare Olympics without no significant post-Olympic economic downturn effects. The paper analyzes the success of the Olympic Games from four main aspects.

First of all, the total economy is the main success factor. Atlanta is a part of Georgia. In 1996, Georgia's total GDP was approximately $\$ 215.2$ billion, while $\$ 5.1$ billion of the total investment of the Olympic Games accounted for less than 3\% of Georgia overall GDP. That is the reason why the Olympic Games had little effect on the state's economy and the extent of boosting economy was not obvious.

Besides, private undertaking. The investment funds of Atlanta Olympics mostly came from the sponsorship of Coca-Cola Company that alleviated a great burden for the state government.

Furthermore, urban residents' consumption view was mature. People can view the impact of the Olympics on the city more rationally without excessive psychological expectations. So, the real estate prices did not significantly raise during the Olympics. There was only slight fluctuations on the price of the hotel industry.

At last, reasonable investment and investment reuse. During the preparations, the State government and sponsor evaluated carefully. On one hand they invested reasonably and avoided wasting. On the other hand, they arranged the projects reasonably, which had to be invested, to strove to be able to get good use after the Olympics.

\section{Sydney Olympic Games in 2000}

Sydney Olympic Games was evaluated as "the most successful Olympic Games" by Mr. Samaranch and also considered as the most profitable by media. However, within six months of the end of the Olympic Games, GDP growth rate in New South Wales fell slightly and it was not significantly rise for many years. After the Olympics, the real estate GDP, the real estate consumption and employment also appeared negative growth. Another obvious dip effect was reflected on the real estate industry. The number of people went to Australia as tourists surged after the successful bid, then many new star-rated hotels and residential buildings were constructed. This also caused that the real estate prices in South Wales grew more than $10 \%$ each year during the seven-year preparations for the Olympic Games. After Olympics, the number of tourists declined sharply and Australia has always been a vast territory so that the housing was not nervous, the real estate industry and real estate prices fell rapidly. This situation continued more than two years, it serious damaged the people's quality of life and affected the healthy development of city. In addition to real estate, the Olympics caused restriction to development of farming and coal mining industry (TABLE I ).

\section{E. Athens Olympic Games in 2004}

Greek economic environment was relatively weak and economic wasn't develop enough. Whether the Olympics can be successfully hosted was concerned and questioned by the worldwide. In the end, though the Olympics convened successfully, its impacts on Greek economy and the postOlympic economy dip effects were particularly significant.

First, because the infrastructure was relatively backward, Greece had to invest a lot on constructing. Second, Athens Olympics was the first Olympic Games after the United States "9 11 " event. The increased $\$ 1.5$ billion security costs made the Greek government worse. Even worse, the Greek government needs to bear $83 \%$ of the cost on the total investment (Fig.1); it was the highest proportion in all Olympic Games. These problems led directly to the Greek government up to $6.1 \%$ in fiscal deficit in 2004 .

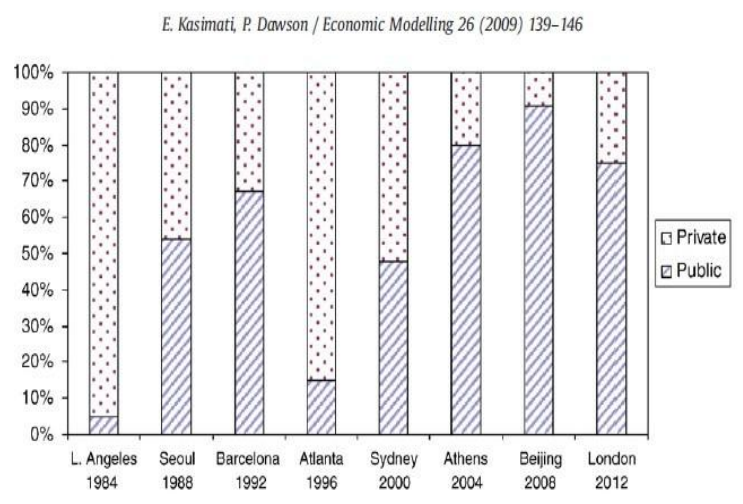

Figure 1. the ratio between government investment and private investment in each Olympic city

TABLE I. THE MAJOR IMPACT ON MAIN INDUSTRY OF OLYMPIC GAMES

\begin{tabular}{|c|c|c|c|c|}
\hline proportional change in growth & \multicolumn{2}{|c|}{ Export } & \multicolumn{2}{c|}{ Employment } \\
\hline Project & South Wales & Australia & South Wales & Australia \\
\hline Farming & -0.202 & -0.26 & -0.338 & -0.409 \\
\hline Coal mining industry & -0.954 & -0.693 & -1.2 & -1.052 \\
\hline handicraft industry & 0.034 & -0.052 & 0.005 & -0.071 \\
\hline Public facilities & 0.143 & 0.004 & 0.097 & -0.019 \\
\hline
\end{tabular}


There are some data revealing that Greek GDP, private consumption, government investment and consumption indicators showed a downward trend since 2004, the postOlympic effect first emerged, but its impact was far more. In 2008, the proportion of GDP growth in Greece has dropped from $4.3 \%$ in 2007 to $1 \%$, and the deficit rose to $9.8 \%$ of GDP, in 2009 soared to $15.4 \%$ of GDP. And the debt levels in 2008 and 2009 were respectively at $110.7 \%$ and $127.1 \%$ of the gross domestic product. This result had greatly restricted the economic development of the whole country.

\section{F. Beijing Olympic Games in 2008}

Compared with other hosted cities, the investment of the Beijing Olympic Games was the biggest, up to $\$ 38$ billion. In order to hold the Olympics successfully, both the public transport and infrastructure transformed into the unprecedented modernization. From this perspective, the Olympics had made a great contribution to Beijing's economic development.

However, post-Olympic economic dip effects were obvious. It mainly displayed in the following aspects. In the stock market, after the Olympic Games, China's stock market fell from 6300; the minimum is fewer than 2000 points. There was no doubt that it had a great influence on Chinese economy. In the real estate industry, the average housing price began to appear inflection point from 2004, housing prices began to increase and the average house price bubble was $49.6 \%$. It affected people's quality of life as well as their attitude to life seriously. What's more, the low utilization rate of stadiums was also an obvious problem. Although $20 \%$ of stadium were established in universities in Beijing, after the Olympics, the problem of low utilization of venues still didn't avoid. Reuters pointed out in a report in April 2012 that the Bird's Nest and the Water Cube operated actively in several ways, but for the present progress, it costs at least 30 years to recover the construction costs in the Bird's Nest, not to mention that utilization is even worse in other venues.

\section{RELATIONSHIP BETWEEN THE POST-OLYMPIC ECONOMIC DOWNTURN EFFECTS AND STOCK MARKET TRENDS}

As the barometer of national economy, the stock market is widely considered that it can react to the whole expected market economy. With the main stock index, the overall profile of a country's economy in a period can be known.

Shanghai Composite Index, Athens Stock Exchange General Indexes, the Standard \& poor's / Australian Stock Exchange 200,the Dow Jones Industrial Average, Spain MA Madrid Index and the KOSPI Index are chosen to analyze the stock market performance.

Daily stock data of the major indexes for 8 years (approximate 2100 trading days) is selected. The data is divided into three stages, the preparatory period(five years before the Olympics), during the Olympic Games and the post-Olympic period (two years after the Olympics).

The paper shows the stock charts in each host city during eight years after getting the data. After careful observation, a phenomenon can be found that after the opening of the
Olympic Games, there is a significant increased process of stock markets, then two years after the end of Olympics there are an inflection point, a wave of rapid downward trend and it is accompanied by a minimum value in a year. (Fig.2 and Fig.3 show the changes of stock in two Olympic Games). The paper does the research on the peak and compare each timing of inflection point after getting the rules.

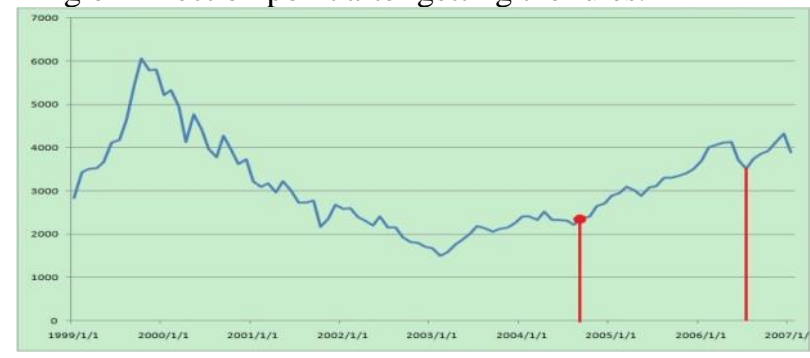

Figure 2. Athens

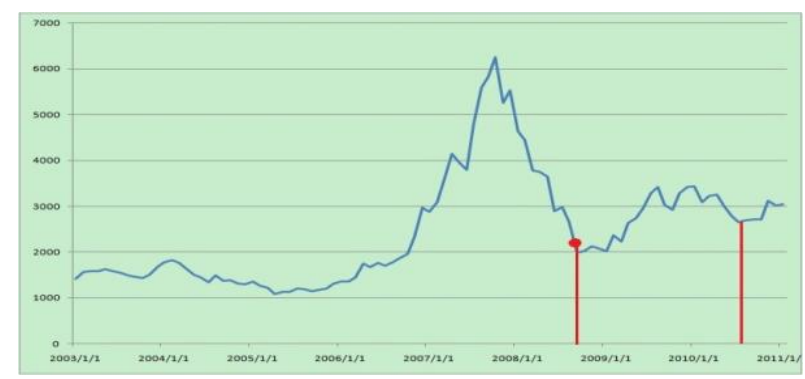

Figure 3. Beijing

In order to quantify peak and compare the timing of the inflection points of each index, the paper processes the data of main stock index further. First to explain is that the paper emphasizes on the relationship between economic dip effects and the stock markets after the Olympic Games, so in the following analysis, it only focus on the changes in the stock index after the opening of the Olympic Games so that laws of the stock index can be analyzed objective to provide basis for forecasting for Rio Olympics. The data processing method is as follows, the stock index $\left(\mathrm{T}_{0}\right)$ on opening day is taken as the starting reference point and every day's stock index $\left(\mathrm{T}_{\mathrm{i}}\right)$ is divided by price on the opening day $\left(\mathrm{T}_{0}\right)$ to get $\mathrm{Ai}$. $\mathrm{Ai}$ is the vertical axis; the interval to the opening ceremony is the abscissa.

The results are shown in Fig.4. After the opening of each Olympics, the national stock index will be a slow rise and

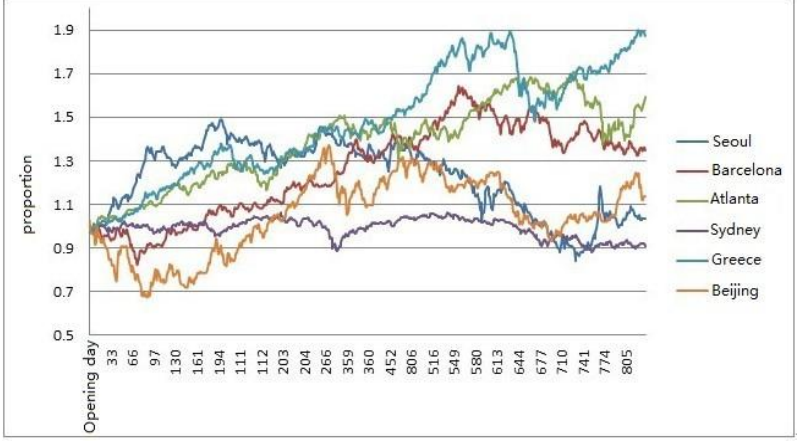

Figure 4. change in proportion of the stock index price 
TABLE II. PEAK RATIO AND TIME POINT

\begin{tabular}{|c|c|c|c|c|c|c|}
\hline Post-Olympic stock market summary & Seoul & Barcelona & Atlanta & Sydney & Greece & Beijing \\
\hline The highest proportion & 1.491 & 1.643 & 1.706 & $\underline{1.063}$ & $\underline{1.899}$ & 1.371 \\
\hline The prominent fluctuations date (i) & 731 & $\underline{824}$ & 773 & 785 & $\underline{670}$ & 696 \\
\hline
\end{tabular}

start a rapid decline in nearly two years. The clear fluctuation dates are concentrated in about two years after the Olympics. It can be understood that the driving effects of Olympics will weaker and weaker with the closing of the Olympics. Sorts of problems which caused by over-investment and excessive expect become obvious. The negative effects are greater than the positive effects of the Olympics, this results in the rapid decline of the stock markets.

The outliers should be removed in order to predict the stock market changes after the Rio Games accurately (the underlined data in TABLE II ). After the Olympics, the growth proportion interval of each host country's main stock index is [1.37,1.71], the fluctuations occur during [696,785] days after the Olympics.

\section{CONCLUSION}

Through the above analysis, it can conclude as following. The smaller economic aggregate of host country is, the more economic risks the country will have. Post-Olympic economic downturn effects not only exist in the economic immaturity city, but also exist in those mature economies such as Australia. Governments should not only regulate the whole investment planning, but also stabilize market environment and guide people to have reasonable expectations to the Olympics to avoid post-Olympic economic downturn effects.

After analyzing each host country's main stock index, the paper shows two important conclusions. First, after the Olympics, main stock index will experience a slow rise and then turning point appears around two years after the end of Olympics. Second, the growth proportion interval of each host country's main stock index is [1.37,1.71], the fluctuations occur during [696,785] days after the Olympics.

\section{ACKNOWLEDGMENT}

This research was supported the Funding Project for Research Level's Improvement by CUEB, and the Beijing Municipal Education Commission Foundation of China (No. KM201110038002). It was also supported by the Beijing Natural Science Foundation Project (Research on realization path of Beijing information resources carbon emissions goal based on ability certification of carbon management), the Beijing Municipal Education Commission Foundation of China (No.KM201110038002), and Level of Scientific Research Improving Project of Beijing Municipal Education Commission.

\section{REFERENCES}

[1] Changjie Zhao. the post-Olympic economic downturn effect discrimination. Sports and Science.2009

[2] Kasimati, Dawson. Assessing the impact of the 2004 Olympic Games on the Greek economy: A small macroeconometric model

[3] Xiaogang Zha. Greek debt crisis: causes, effects, revelation.2011

[4] Nishio, Lim and P. Downward, Analyzing the Economic Impact of the Olympics Using Stock Market Indices of Host Countries. 2009

[5] John R Madden and Matthew Crowe, Estimating the Economic Impact of the Sydney Olympic Games.2005 